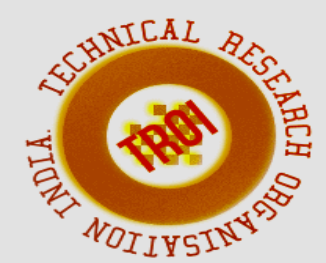

\title{
REDUCTION OF TRAFFIC AT TOLL PLAZA BY AUTOMATIC TOLL COLLECTION USING RFID AND GSM TECHNOLOGY
}

\author{
ManjunathSingh. $\mathrm{H}^{1}$,Velantina. $\mathrm{V}^{2}$,VedaBai. ${ }^{3}$,Varshini.m.naik ${ }^{4}$,Padmavathi. $S^{5}$ \\ ${ }^{1}$ Assistant Professor, ${ }^{2,3,4,5}$ Students , \\ Departement of Computer Science and Engineering, \\ Dr.T.Thimmaih Institute of Technology KGF \\ Emailid: ${ }^{1}$ mansh.singh@gmail.com
}

\begin{abstract}
Internet of things is an integral part in today's development of smart city, now without internet is became like nothing is possible in the world especially for corporate systems where they use internet for communication purpose. Internet communicates through radio waves, line of sight not required. Internet of things (IoT) is expanding it's outreach to every aspect of our daily life and our needs. The IoT energy consumption can also be reduced by utilizing network coding in Internet of things in dayto -day life. In Automatic Toll collection system uses RFID technology where they help to reduce the Toll gate traffic and avoid other illegal passage of vehicles through a Toll gate. This paper shows, for the first time, that Toll booth can be completely managed using the 'Internet of Things' concept based on the RFID technology.
\end{abstract}

Keywords: RFID Reader, GSM, RFID Tag, Aurdino Uno, LCD display.

\section{INTRODUCTION}

Transportation is the major contributor to the nation's economy. Improvements in the field of transportation enabled us to have a fast pace lifestyle characterized by exceptional independence of movement, huge trades in manufactured goods and services, high jobs and social movements. The nation's economic treasure can be said to be directly proportional to the productive transportation methods. As we know numbers of vehicles on the road are increasing day by day, problems such as congestion, accidents, air pollution have become a major factor of concern.

Because of the major development in Roadways, there is an increase in the number of toll plazas and leading to have long queues in toll plazas and causing money leakage which leads to more delay. We have designed an IOT based Toll booth Manager System in which a person can use an RFID to pay the Toll charge. When the RFID is swiped, the system would check if it has sufficient balance and then deduct the toll charge and update the balance through IOT.Internet of Things (IoT) is basically the 'things' which are connected to networks and can exchange data with the help of sensors, electronics, software and connectivity. These systems do not require any human interaction. A trend of IoT Technology is found in many industries like healthcare, Energy, Transportation etc. Here the data of the RFID card is sent to the website, through network interconnected with IOT.

\section{EXISTING SYSTEM}

Designed a programming board to program the PIC controller microcontroller. This consists of JTAG in Spy-Bi-Wire mode. When the power supply is connected with fuse blow protection, additionally, the port pins were attached with a single pole single thrown (SPST) switch and LED for testing the code visually. The IR transmitter/LED is a device that used to emit infrared light outside the visible spectrum. The device that is used to detect or receive the IR light is called infrared sensor which sense aspects of its surroundings. In our example, the IR sensor is used to detect arriving vehicles. The SE555P Timer by Texas Instruments is used in 
the monostable mode. When IR radiation is received ("no vehicle" condition) triggering occurs, resulting in a high output. When a vehicle arrives at a toll plaza, the IR rays are blocked by the vehicle, and the output of the timer to toggle to low. The change in output of the timer is sensed by the microcontroller, which is programmed to turn on the IR transmitter.

DISADVANTAGE

- Time delay

- Does not applicable for wide range application

\section{PROPOSED SYSTEM}

IOT Based Toll Booth manager system helps the toll booths to collect the toll by just swiping a card. The project contains four of the keys by which the user can select the mode of toll collection. Once the RFID mode is selected, the LCD displays the message to show the RFID card. The card should be then swiped on the Card Reader. Based on the RFID card payment light will glow. After the card is swiped, the micro-controller: Arduino will check if the card is valid or not. If the card is valid then the micro-controller will check if the card has sufficient balance. The balance of the card is displayed on the LCD display. Once the micro-controller detects sufficient balance, the toll gate is opened and the vehicle is allowed to pass through.

ADVANTAGE

- User friendly

- Easy to install

\section{BLOCK DIAGRAM}

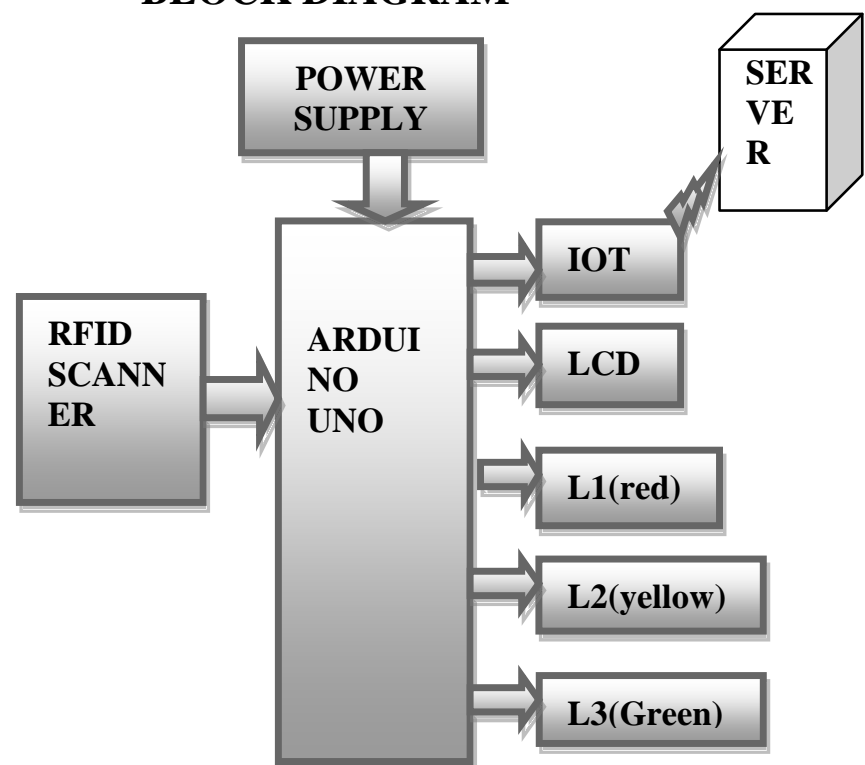

Figure 1. Block diagram of ATCS

\section{METHODOLOGY}

\section{AURDINO UNO}

The Arduino UNO is open-source microcontroller board based and the Microchip ATmega328P microcontroller, Which is developed by Arduino.cc. This board is equipped with sets of digital and analog input/output (I/O) pins that may be interfaced between various expansion boards (shields) and other circuits, and this board contains 14 Digital pins, 6 Analog pins, and programmable with the Arduino IDE (Integrated Development Environment) via a type B USB cable.

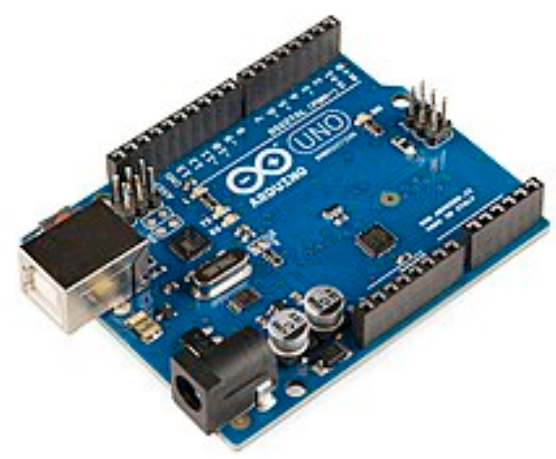

Figure 2. Aurdini Uno

\section{SPECIFICATION}

- Microcontroller: Microchip ATmega328P

- Operating Voltage: 5 Volt

- Input Voltage: 7 to 20 Volts

- Digital I/O Pins: 14 Analog Input Pins: 6

- DC Current per I/O Pin: 20 mA

- DC Current for 3.3V Pin: $50 \mathrm{~mA}$

- SRAM: 2 KB

- EEPROM: $1 \mathrm{~KB}$

- Clock Speed: $16 \mathrm{MHz}$

- Length: $68.6 \mathrm{~mm}$

- Width: $53.4 \mathrm{~mm}$

- Weight: $25 \mathrm{~g}$

\section{LIQUID CRYSTAL DISPLAY}

LCD (Liquid Crystal Display) screen is an electronic display module and find a wide range of applications. A $16 x 2$ LCD display is very basic module and is very commonly used in various devices and circuits. These modules are 
preferred over seven segments and other multi segment LEDs.

A 16x2 LCD means it can display 16.

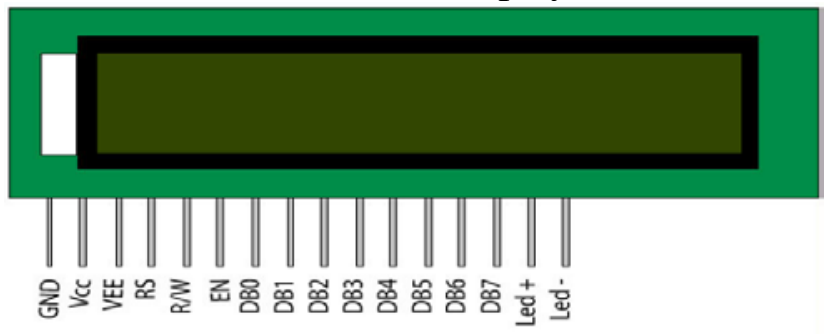

Figure 3.LCD

Characters per line and there are 2 such lines. In this LCD each character is displayed in $5 x 7$ pixel matrix. This LCD has two registers, namely, Command and Data.

\begin{tabular}{|c|c|c|}
\hline - $\quad$ Pin No & Function & Name \\
\hline 1 & Ground (0V) & Ground \\
\hline 2 & $\begin{array}{l}\text { Supply voltage; } \\
5 \mathrm{~V}(4.7 \mathrm{~V}-5.3 \mathrm{~V})\end{array}$ & Vcc \\
\hline 3 & $\begin{array}{l}\text { Contrast } \\
\text { adjustment; } \\
\text { through a } \\
\text { variable resistor }\end{array}$ & $\mathrm{V}_{\mathrm{EE}}$ \\
\hline 4 & $\begin{array}{l}\text { Selects command } \\
\text { register when } \\
\text { low; and data } \\
\text { register when } \\
\text { high }\end{array}$ & $\begin{array}{l}\text { Register } \\
\text { Select }\end{array}$ \\
\hline 5 & $\begin{array}{l}\text { Low to write to } \\
\text { the register; High } \\
\text { to read from the } \\
\text { register }\end{array}$ & Read/write \\
\hline 6 & $\begin{array}{l}\text { Sends data to data } \\
\text { pins when a high } \\
\text { to low pulse is } \\
\text { given }\end{array}$ & Enable \\
\hline 7 & \multirow{8}{*}{ 8-bit data pins } & DB0 \\
\hline 8 & & DB1 \\
\hline 9 & & DB2 \\
\hline 10 & & DB3 \\
\hline 11 & & DB4 \\
\hline 12 & & DB5 \\
\hline 13 & & DB6 \\
\hline 14 & & DB7 \\
\hline 15 & $\begin{array}{l}\text { Backlight } \\
\mathrm{V}_{\mathrm{CC}}(5 \mathrm{~V})\end{array}$ & Led+ \\
\hline 16 & $\begin{array}{l}\text { Backlight Ground } \\
\text { (0V) }\end{array}$ & Led- \\
\hline
\end{tabular}

\section{NODE MCU}

NodeMCU is a LUA based interactive firmware for Expressif ESP8622 Wi-Fi SoC, as well as an open source hardware board that contrary to the $\$ 3$ ESP8266 Wi-Fi modules includes a CP2102 TTL to USB chip for programming and debugging, is breadboard-friendly, and can simply be powered via its micro USB port.NodeMCU is a wifi SOC (system on a chip) produced by Espressif Systems. It is based ESP8266 -12E WiFi module. It is an highly integrated chip designed to provide full internet connectivity in a small package.

\section{RFID READER:}

An RFID reader's function is to interrogate RFID tags. The means of interrogation is wireless and because the distance is relatively short; line of sight between the reader and tags is not necessary. A reader contains an RF module, which acts as both a transmitter and receiver of radio frequency signals. The transmitter consists of an oscillator to create the carrier frequency; a modulator to impinge data commands upon this carrier signal and an amplifier to boost the signal enough to awaken the tag.

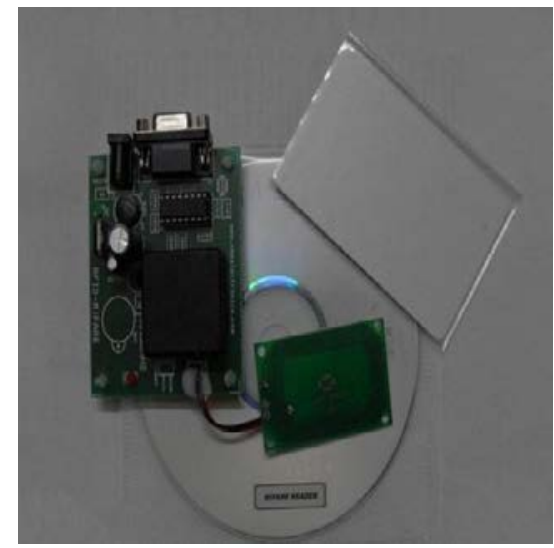

Figure 4.RFID Reader

\section{RFID TAG:}

An RFID tag is a microchip combined with an antenna in a compact package; the packaging is structured to allow the RFID tag to be attached to an object to be tracked. "RFID" stands for Radio Frequency Identification. The tag's antenna picks up signals from an RFID reader or scanner and then returns the signal, usually with some additional data (like a unique serial number or other customized information).RFID tags can be very small - the size of a large rice grain. 


\section{LED}

A light-emitting

diode (LED)

is

a semiconductor light source that emits light when current flows through it. Electrons in the semiconductor recombine with electron holes, releasing energy in the form of photons. This effect is called electroluminescence.

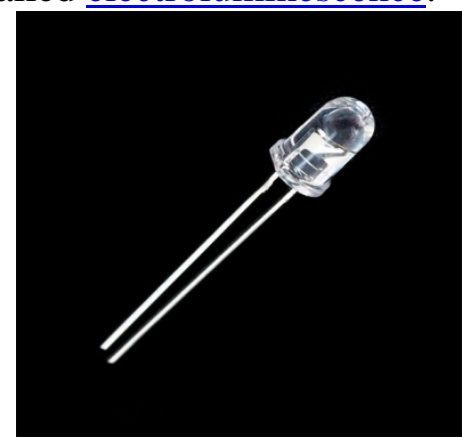

Figure 5.LED

Alternate pairs of diodes conduct, changing over the connections so the alternating directions of $\mathrm{AC}$ are converted to the one direction of DC.

\section{FLOW CHART OF AUTOMATIC TOLL COLLECTION SYSTEM}

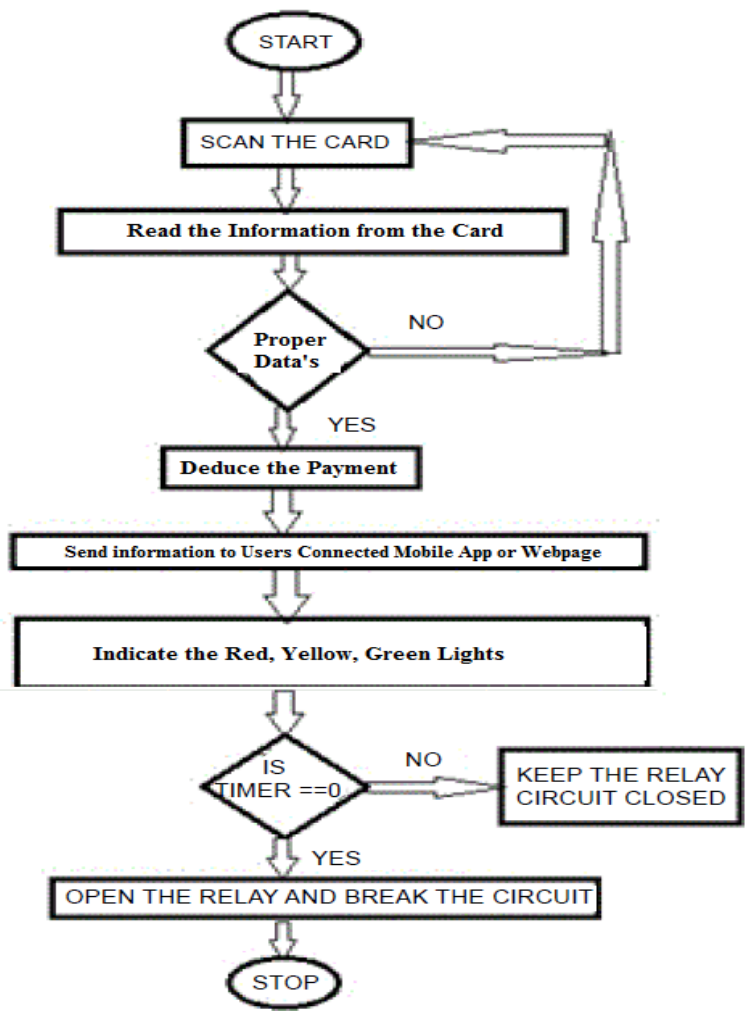

Figure 6.Working Flow of automatic toll collection system

The long queuing of Vehicles to pay toll tax at a highway toll gate is a common observed at toll plazas. The toll collection system mostly works on a manual process, This has a cumulative effect of increasing traffic congestion, adding delays in travel time. To solve this problem we are designing an "Advanced automatic Toll Collection and Vehicle detection System”. This is an automatic system which leverages the "Internet of Things" technology to identify a vehicle via a unique identification tag. The RFID tag is used, in order to identify the vehicle when it passes through a toll booth, the RFID card is used to track \& bill the vehicle owner through a payment gateway.

The Flow chart working is described below

1. A vehicle will approach at the toll booth, The RFID reader at the toll will read the RFID card embedded on the vehicle.

2. Then, it will pass the information stored in the card to the Arduino (microcontroller).

3. Then the Arduino Uno microcontroller will track information and will check whether the card is valid or not.

4. It checks whether the card is valid or not, and whether the card is having sufficient balance or not will be displayed on lcd.

5. Certain the corresponding amount with respect to NH tolls will be deducted from the owner's account. Here, we have fixed the amount.

6. Along with this, a green LED light will be glown with the buzzer, and further the gate will be opened for the vehicle to pass on.

7. GSM module will send message to the owner informing him about amount deducted from their tag.

8. If the card is not valid, the screen will show 'invalid user' and no amount would be deducted, and a red LED light will glow with the buzzer making noise

9. Thus, no command will be sent to the motor.

IOT Based Advanced automatic toll collection and vehicle detection system helps the toll to be collected automatically just by identifying the vehicle through a unique RFID tag detected by RFID scanner as the vehicle approaches. The project consists an application by which the users will the pay the toll amount. Once the RFID detects the vehicle, the LCD displays the message by showing the vehicle's number, Based on the RFID card payment, the light will glow. After this the information present in card is 
passed to micro-controller Arduino, Aurdino will check if the card is valid or not. Then the GSM module will send a message to the owner informing him about amount deducted from their tag, and in case If the card is not valid, the screen will display 'invalid user' on the lcd screen and no amount will be deducted. Along with this, a red LED light will glow with the buzzer making noise Thus, no command will be sent to the motor.

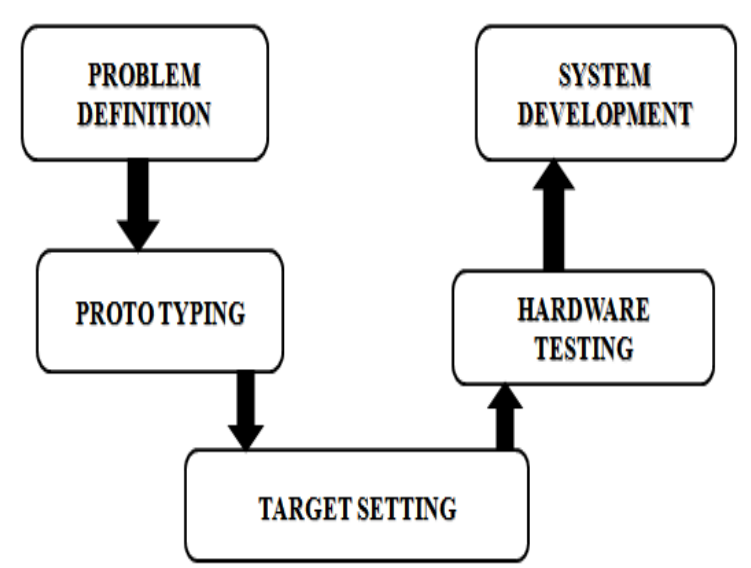

Figure 7. General methodology steps

The diagram gives a general view of methodology

1. Problem Definition: Finding the problem that is identified in toll plaza, i.e traffic congestion and time consuming due to queuing of vehicles, so to solve this problem ATCS is introduced.

2. Proto Typing: Prototyping the project or circuitry that is done through available hardware.

3. Target Setting: The goal for working of the project.

4. Hardware Testing: Setting up hardware at initial stages and then interfacing the hardware with each other for developing proper system.

\section{CONCLUSION}

Here we have tried to analyze some of the current RFID toll collection systems and their practicality. All system tries to reduce the traffic overheads at toll plaza. This system had been include some of the benefits to both toll authorities and facility users, in terms of time and cost saving, improved security and high capacity. Today, Transportation is the major contributor to the nation's economy. IoT Toll Collection systems are aimed at automating the toll plazas so as to maintain fairness in the transactions during toll collections. Every industry has its different method of transportation to reduce excessive costs spent on transportation. Thus, providing good quality transportation will significantly contribute to better economy and productivity.

\section{REFERENCES}

[1] Prof. Nivedita Kadam, Miss.Shubhangi Waghmare, Miss.Shradha Adhalkar, Mr. Gunwant Sirsat, Mr.Nikhil Patil "A Survey on Toll Collection System Using Different Method” (IJSRTE) 2017 .

[2] Venkatesh Suvarna "A Review on Various RFID Based Automated Highway Toll Collection Systems" (IJCSIT) International Journal of Computer Science and Information Technologies, Vol. 6 (3) , 2015.

[3] Devyani Bajaj, Neelesh Guptha "GPS Based Automatic Vehicle Tracking using RFID" (IJEIT) International journal of Engineering and Innovative Technology, Vol. 1, 2012.

[4] S. Abirami, K. Amudha, S. Lavanya, R. Deepa "Automatic Toll E-Ticketing System using RFID and GSM Technology” (IJEECS) International journal of Electronics, Electrical and Computational System, Vol. 6, 2017.

[5] Poorvika Bhisikar, AlpitaUmredkar, Ankitha Vidya, Sneha Samrit "Automatic Toll Plaza using RFID” Research Article, IJESC, Vol. 7,2017.

[6] Chandrashekar V “Automatic Toll Collection and Anti Theft Alert System using RFID and Microcontroller” (IRJET) International Research journal of Engineering and Technology, Vol. 4, 2017.

[7] Pranoti Slunke, Poonam Malle, Kirti Datir, Jayashree Dukale "Automated Toll Collection System using RFID” (IOSR-JCE) IOSR journal of Computer Engineering, Vol. 9, 2013.

[8] Surya.K.Narayan, Thushar.C, Sandhya.C, Saranya.N, Sreepriya.P.V "Automatic Tollgate System using RFID and GSM Technology" ISSN, Vol. 2015. 
[9] Prof. D.A.Doshi, Mhaske Mayuri.S, [13] Prof. Chhaya Athavale, Suraj Shinde, Wakchaure Kalyani.S "Electronic Toll Akshay Rajemane, Nishant Mohite "Raspberry Collection System Based on RFID with GSM" Pi Based Smart Toll Collection System" IJARIIE, Vol. 2, 2016.

[10] Vishnupriya.R, Dr.N.P.Ananthamoorthy "Automatic Toll Collection System using RFID and GSM Technology” (IJARCCE) International journal of Advanced Research in Computer and Communication Engineering, Vol. 6, 2017.

[11] Preethi Rajasekaran, Ragavi Pala Janardhan “A Smarter Toll Gate Based on Web Of Things” IEEE, 2016.

[12] Sagar.B.Shinde, Komal Patil, Saundarya Nakka, Lakshmi Dayanandan, Akanksha Ovhale “Toll Automation System Using NFC” , January 2016, Volume 3, Issue 1 JETIR (ISSN-2349-5162) JETIR1601004 Journal of Emerging Technologies and Innovative Research (JETIR). ,International Research Journal of Engineering and Technology (IRJET) ,2017.

[14] Amol A. Chapate, D.D. Nawgaje "Electronic Toll Collection and Theft Detection System on ARM-7 and RFID Technology", International Journal of Advanced Research in Electronics and Communication Engineering (IJARECE) Volume 4, Issue 4, 2015.

[15] Aadish Joshi, Gaurav Bhide, Shreyas Patil, R. D. Komati " IoT Based Toll Booth Management System” International Journal of Electrical, Electronics and Computer Systems (IJEECS), Volume -5, Issue-2, 2017. 